\title{
Kainic Acid-Induced Excitotoxicity Experimental Model: Protective Merits of Natural Products and Plant Extracts
}

\author{
Nur Shafika Mohd Sairazi, ${ }^{1}$ K. N. S. Sirajudeen, ${ }^{1}$ Mohd Asnizam Asari, ${ }^{2}$ \\ Mustapha Muzaimi, ${ }^{3}$ Swamy Mummedy, ${ }^{1}$ and Siti Amrah Sulaiman ${ }^{4}$ \\ ${ }^{1}$ Department of Chemical Pathology, School of Medical Sciences, Universiti Sains Malaysia, Health Campus, \\ Kubang Kerian, 16150 Kota Bharu, Kelantan, Malaysia \\ ${ }^{2}$ Department of Anatomy, School of Medical Sciences, Universiti Sains Malaysia, Health Campus, Kubang Kerian, \\ 16150 Kota Bharu, Kelantan, Malaysia \\ ${ }^{3}$ Department of Neurosciences, School of Medical Sciences, Universiti Sains Malaysia, Health Campus, Kubang Kerian, \\ 16150 Kota Bharu, Kelantan, Malaysia \\ ${ }^{4}$ Department of Pharmacology, School of Medical Sciences, Universiti Sains Malaysia, Health Campus, Kubang Kerian, \\ 16150 Kota Bharu, Kelantan, Malaysia
}

Correspondence should be addressed to K. N. S. Sirajudeen; sirajuden@usm.my

Received 15 July 2015; Revised 16 November 2015; Accepted 17 November 2015

Academic Editor: Shan-Yu Su

Copyright (c) 2015 Nur Shafika Mohd Sairazi et al. This is an open access article distributed under the Creative Commons Attribution License, which permits unrestricted use, distribution, and reproduction in any medium, provided the original work is properly cited.

\begin{abstract}
Excitotoxicity is well recognized as a major pathological process of neuronal death in neurodegenerative diseases involving the central nervous system (CNS). In the animal models of neurodegeneration, excitotoxicity is commonly induced experimentally by chemical convulsants, particularly kainic acid (KA). KA-induced excitotoxicity in rodent models has been shown to result in seizures, behavioral changes, oxidative stress, glial activation, inflammatory mediator production, endoplasmic reticulum stress, mitochondrial dysfunction, and selective neurodegeneration in the brain upon KA administration. Recently, there is an emerging trend to search for natural sources to combat against excitotoxicity-associated neurodegenerative diseases. Natural products and plant extracts had attracted a considerable amount of attention because of their reported beneficial effects on the CNS, particularly their neuroprotective effect against excitotoxicity. They provide significant reduction and/or protection against the development and progression of acute and chronic neurodegeneration. This indicates that natural products and plants extracts may be useful in protecting against excitotoxicity-associated neurodegeneration. Thus, targeting of multiple pathways simultaneously may be the strategy to maximize the neuroprotection effect. This review summarizes the mechanisms involved in KA-induced excitotoxicity and attempts to collate the various researches related to the protective effect of natural products and plant extracts in the KA model of neurodegeneration.
\end{abstract}

\section{Introduction}

Neurodegeneration involves the progressive loss of structure and function of neurons. Various types of biological mechanism have been implicated in neurodegeneration. Excitotoxicity is considered to be a major mechanism of neuronal death in acute and chronic neurodegenerative diseases, such as Alzheimer's disease (AD), Parkinson's disease (PD), Huntington's disease (HD), temporal lobe epilepsy (TLE), and amyotrophic lateral sclerosis (ALS) [1]. The concept of "excitotoxicity" was formulated by Olney in 1969 [2] which was referred to as a neuronal degeneration triggered by the over- or prolonged activation of glutamate receptors in the central nervous system (CNS) by excitatory amino acids.

Glutamate is a major excitatory neurotransmitter that mediates fast synaptic transmission and plays an important role in the mammalian CNS (brain and spinal cord) [3, 4]. Excess glutamate is highly toxic to neurons. Glutamate acts through glutamate receptors. There are two major classes of glutamate receptors: ionotropic glutamate receptors 


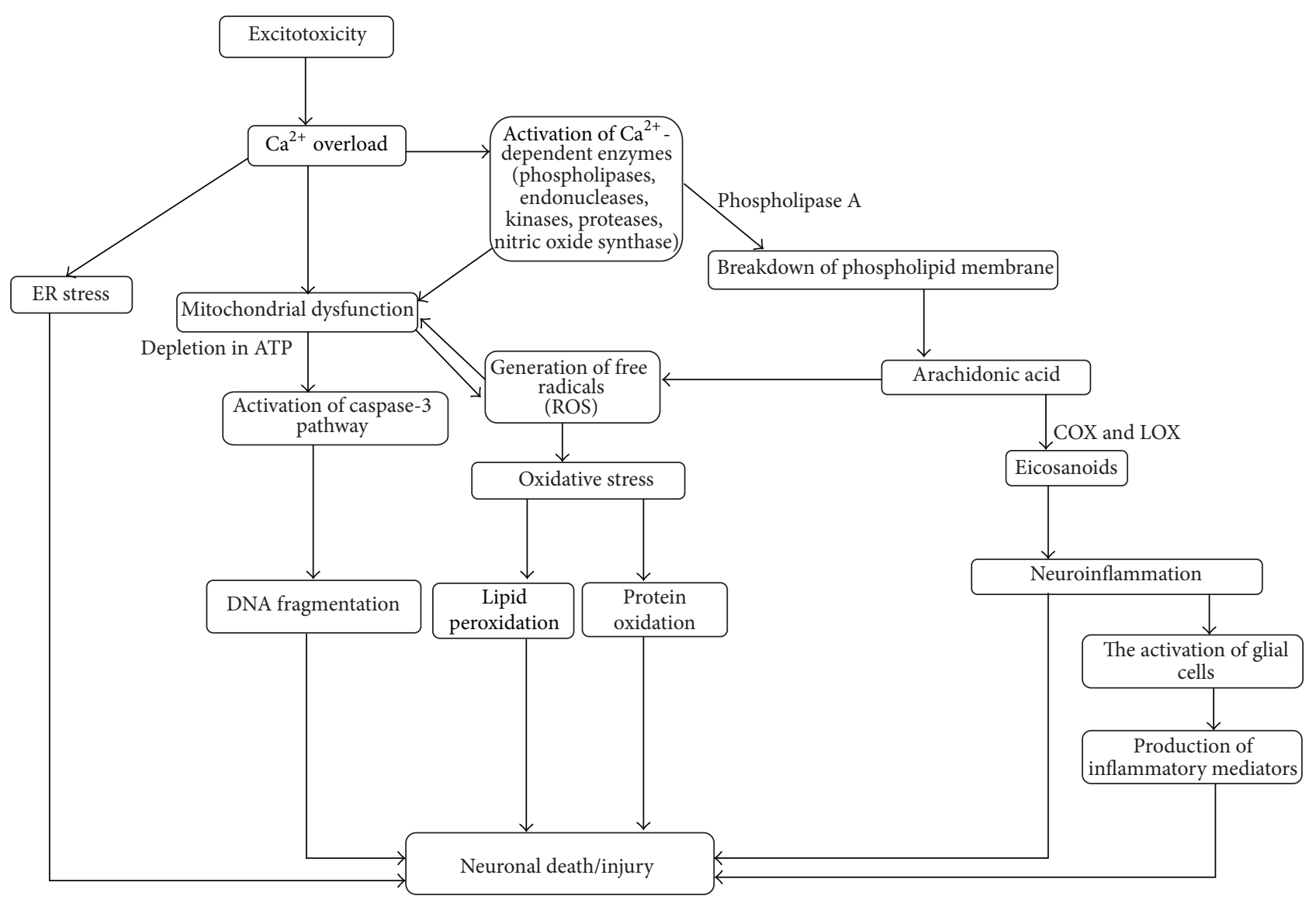

FIGURE 1: Proposed mechanism of action in KA-induced excitotoxicity.

(iGLURs) and metabotropic glutamate receptors (mGLURs). These glutamate receptors differed in terms of their functionality. iGLURs mediate fast postsynaptic potentials by activating ion channels directly, while mGLURs mediate slow postsynaptic potentials by coupling to intracellular $\mathrm{G}$ proteins and second messengers $[5,6]$. iGLURs can be divided into three subtypes: N-methyl-D-aspartic-acid (NMDA) receptors, $\alpha$ amino-3-hydroxy-5-methyl-4-isoxazole propionate (AMPA) receptors, and kainate receptors. They are generally named after their specific ligand and by the types of their activating agonists $[7,8]$.

In the animal models of neurodegeneration, excitotoxicity is commonly induced experimentally by chemical convulsants, particularly by kainic acid (KA) [9]. Administration of KA has widely been used as a tool to explore the mechanism involved in excitotoxicity.

\section{Kainic Acid-Induced Excitotoxicity Model}

KA [2-carboxy-4-(1-methylethenyl)-3-pirrolidiacetic acid] is a structural L-analog of glutamate and an agonist of kainate subtype of ionotropic glutamate receptors. KA exerts its neuroexcitatory property by binding to kainate receptors, which have presynaptic modulatory and postsynaptic excitatory actions $[10,11]$. KA activates glutamate receptors and the overactivation of glutamate receptors produces neuronal membrane depolarization. This causes the influx of calcium ion $\left(\mathrm{Ca}^{2+}\right)$ and subsequently triggers excitotoxic neuronal death cascade events (refer to Figure 1).

Studies in KA-induced animal experimental model have shown that administration of KA resulted in seizures [1215], behavioral changes of rodents [16-22], oxidative stress [23-25], glial activation [26-32], production of inflammatory mediators $[32,33]$, endoplasmic reticulum (ER) stress [34-37], mitochondrial dysfunction, and selective neuronal degeneration in the brain of rodents [15, 36, 38-40].

Administration of $\mathrm{KA}$ is known to induce a sequence of well-characterized seizure syndromes and has resulted in behavioral changes of rodents including motor and cognitive performance $[15,17-20]$. A single systematic injection of a convulsive dose of KA has resulted in limbic status epilepticus (SE), initiating neuropathological changes in limbic brain areas and subsequently long-term spontaneous recurrent seizures (SRSs) in both rat [40] and mice [41] as well as neuropathological lesions reminiscent of those found in patients with TLE $[15,42]$. KA-induced SE causes irreversible neuronal degeneration in the selective brain areas, particularly in limbic structures (i.e., in the CA1 and CA3 regions of hippocampus and the hilus of dentate gyrus (DG)) [15].

Several studies have also demonstrated that there are behavioral changes in rodents after $\mathrm{KA}$ administration that 
resulted in memory deteriorations in the elevated plus-maze [16], increase in the activity in the open field test [21], and cognitive impairment in the passive avoidance test [22] and in Morris water maze task [17-20].

Oxidative stress may have a contributory role in neuronal and glial cell death [23-25, 43, 44]. There are growing evidences to suggest that oxidative stress has been implicated in the mechanism of excitotoxicity on different brain regions after the induction of KA on rodents [23-25]. The brain is considered to be very vulnerable to oxidative stress because of its great consumption of energy, oxygen, and glucose, large amount of peroxidizable polyunsaturated fatty acids, and relatively low antioxidant capability [45].

Oxidative stress occurs when there is disturbance in balance between antioxidant mechanism and the production of free radicals and redox status. KA acts on and activates kainate receptors to incite the influx of intracellular calcium. The entry of intracellular calcium can stimulate the formation of free radicals.

Overactivation of glutamate receptors by KA has resulted in the increased production of reactive oxygen species (ROS), the mediators of oxidative stress [24]. Oxidative stress can cause cellular damage and generation of ROS, which oxidizes membrane lipids, protein, and DNA. Increased level of intracellular $\mathrm{Ca}^{2+}$ also leads to the activation of several $\mathrm{Ca}^{2+}$ dependent enzymes [46]. Those enzymes include proteases (responsible for breaking down membrane and cytoskeletal proteins), endonucleases (responsible for DNA fragmentation), kinases, phospholipases (responsible for membrane damage), phosphatases, and nitric oxide synthase (NOS) [4648].

Glial activation and neuroinflammation are believed to contribute to the development and progression of acute and chronic neurodegeneration [49-53]. Upon neuronal injury, neurons interact with glial cells (i.e., astrocytes and microglia). The survival of neurons and the postinjury repair of neurons are influenced by the activity of astrocytes and microglia. The activation of glial cells (as measured by increased activation of microglia and astrocytes) is associated with neuronal death upon KA administration [30-32]. Systemic injection of KA on rats has resulted in large increase of reactive astrocytes and microglial cell [54]. Activated microglia and astrocytes produced a large amount of inflammatory mediators, such as nitric oxide (NO), interleukin-1 beta (IL-1 $\beta$ ), and tumor necrosis factor-alpha (TNF- $\alpha$ ) [55], which influence the outcome of neurodegeneration [32,33].

The overactivation of glutamate receptors by KA can also cause the fragmentation of ER membrane and ER stress with the activation of ER proteins like binding immunoglobulin protein (BiP, also known as glucose-regulated protein 78/GRP78), CCAAT/enhancer-binding protein- (C/EBP-) homologous protein (CHOP, also known as growth arrest and DNA damage inducible gene 153/GADD153), and caspase-12, which are involved in the neuronal apoptosis [34,35].

Excessive influx of $\mathrm{Ca}^{2+}$ into neurons through ionic channels and generation of free radicals also cause the accumulation of $\mathrm{Ca}^{2+}$ and mitochondrial dysfunction, which leads to the collapse of potential at the mitochondrial inner membrane. This results in the mitochondrial swelling and the release of mitochondrial factors at the mitochondrial inner membrane space. The release of mitochondrial factors also triggers the activation of caspase and proteases that are responsible for the activation of apoptotic neuronal death. This leads to the cleavage of essential cellular substrates such as poly(ADP-ribose) polymerase-1 (PARP-1).

In a study by Gilliams-Francis et al. the intracerebral injection of KA has resulted in DNA damage, PARP-1 activation, and neuronal death [56]. The work suggested that there is a link between activation of caspase pathways and excitotoxic cell death and the neurons undergo caspase-mediated death, involving the DNA fragmentation and cleavage of PARP-1.

KA administration also causes mitochondrial dysfunction. Excessive generation of ROS causes reduction in energy level (depletion in ATP) and lipid peroxidation which leads to mitochondrial dysfunction [36]. These alterations in the mitochondrial function could be an early event prior to neuronal cell death.

\section{The Mechanism of Preventive and Therapeutic Treatment Approaches in Neurodegeneration}

Since excitotoxicity is an important process in the pathogenesis of neurodegeneration, neuroprotection seems promising for the preventive and therapeutic approaches in neurodegenerative diseases. Neuroprotection offers the potential to ameliorate or delay the process of neurodegeneration or to slow the rate of neurodegeneration through the interaction with the pathological changes process as well as the progression of clinical manifestations of the neurodegeneration diseases.

Considering the implication of oxidative stress in the mechanism of excitotoxicity-associated neurodegeneration, antioxidants and anti-inflammatory agents serve as potential candidates for neurodegeneration preventive and therapeutic treatment. Antioxidants would serve as agents that can inhibit the production of free radicals, interfere with formed free radicals, and limit the degree of damage to neurons [57].

In addition, inflammation can enhance the neuronal death and neuronal degeneration through the production of inflammatory mediators, such as cytokines and prostaglandin. The reduction of inflammation via cyclooxygenase2 (COX-2) and 5-lipoxygenase (5-LOX) activities could also decrease inflammatory molecules, including prostanoids. Glia-derived cytokines can also counteract inflammation to block the unique signal transduction of specific proinflammatory cytokines and can also modify the outcome of neurodegeneration progression.

Other potential approaches for treatment of neurodegenerative diseases are to improve the function of mitochondria and ER to inhibit the ER stress and apoptosis. A short summary and illustration of the proposed mechanism of action for the preventive and therapeutic strategies for neurodegenerative diseases are presented in Table 1 and Figure 2. Combination of multiple agents that target multiple 


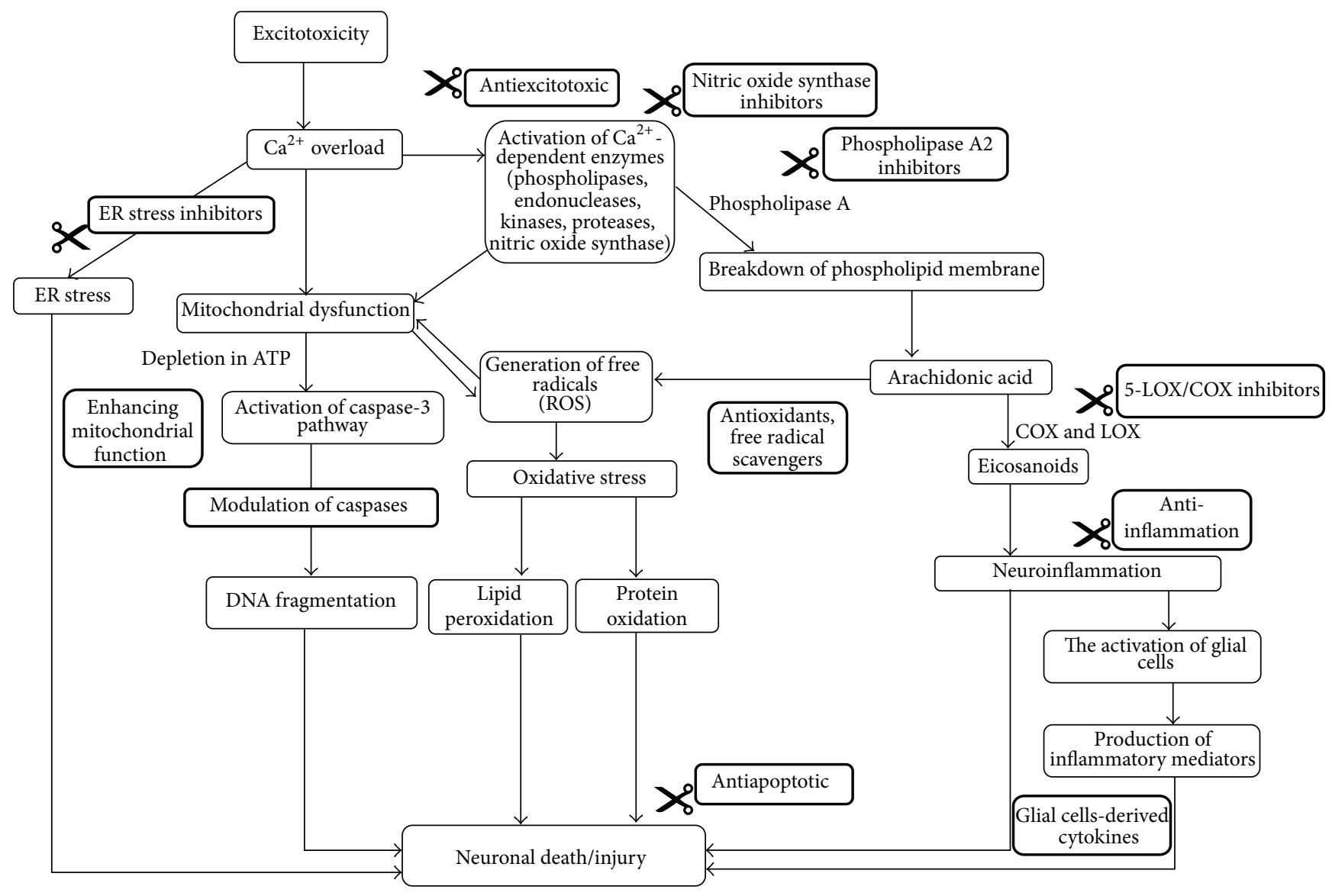

FIGURE 2: Illustrations of proposed mechanism of preventive and therapeutic treatment approaches in neurodegeneration.

TABLE 1: Proposed mechanisms of preventive and therapeutic treatment approaches in neurodegeneration.

\begin{tabular}{lc}
\hline Proposed mechanisms & Reference(s) \\
\hline Anti-inflammation & {$[87-95]$} \\
Antioxidant activity & {$[25,96-102]$} \\
& {$[14,15,42$,} \\
Anticonvulsion and antiepileptic & $64,70,72$, \\
& $103,104]$ \\
Modulation of apoptosis-related genes/proteins & {$[74,75,84$,} \\
and signaling pathways & $104-111]$ \\
Cognitive enhancer & {$[17-20,22]$} \\
Manipulation of glial activation and inflammatory & {$[29,72,112-$} \\
cytokines & $115]$ \\
Combating excitotoxicity & {$[116]$} \\
Enhancing mitochondrial functions & {$[36,111]$} \\
Inhibition of ER stress by small molecular & {$[34-37]$} \\
compounds & \\
Inhibition of Phospholipase A by Phospholipase & {$[117]$} \\
A inhibitors & {$[118]$} \\
Inhibition of NO by NOS inhibitors &
\end{tabular}

pathways may result in synergistic effects to bring additive neuroprotective effect.

\section{The Protective Effect of Natural Products and Plant Extracts in the KA Model of Neurodegeneration}

For decades, many efforts attempted to elucidate the mechanism of excitotoxicity and neurodegeneration and to investigate its pharmacological interventions. Recently, there has been an emerging trend to search for natural resources to combat against neurodegenerative diseases. Reports on the potential beneficial effects of natural products and plant extracts in the experimental treatment of neurodegeneration continue to expand, largely on the effect by various constituents, including polyphenols for a wide range of medicinal, pharmacological, and biological properties. The following are summaries of the various reported studies on selected natural products and plant extracts involving the KA-induced experimental neurodegeneration model, namely, ginseng, Uncaria rhynchophylla, tea, and honey bee propolis.

4.1. Ginseng (Panax sp.). Ginseng is the dried root of several species from Panax genus (Araliaceae family). There are seven major species to Panax genus but Panax ginseng (Asian ginseng), Panax quinquefolius (American ginseng), and Panax japonicus (Japanese ginseng) are the three most 
widely studied species [58-60]. The major active components found in ginseng are ginsenosides (steroidal saponins) [61]. The rest are polysaccharides, peptides, polyacetylenic alcohol, and fatty acids [58, 60, 61]. Ginsenosides have been isolated and classified into three groups, based on chemical structure of their sapogenins (aglycones): the panaxadiols group (i.e., $\mathrm{Rb}_{1}, \mathrm{Rb}_{2}, \mathrm{Rb}_{3}, \mathrm{Rc}, \mathrm{Rd}, \mathrm{Rg}_{3}, \mathrm{Rh}_{2}$, and $\mathrm{Rh}_{3}$ ), the panaxatriols group (i.e., $\mathrm{Re}, \mathrm{Rf}, \mathrm{Rg}_{1}, \mathrm{Rg}_{2}$, and $\mathrm{Rh}_{1}$ ), and the oleanolic acid group (i.e., Ro) [62]. Ginseng has been shown to possess antioxidants and anti-inflammatory properties [58]. Pharmacological effects of ginseng have been demonstrated on the CNS, with stimulatory effects and neurotransmission modulation [63].

In KA-induced excitotoxicity model, Lee et al. work in 2002 was the first to suggest that ginseng may have anticonvulsant activity [64]. It reported that KA-induced seizure in animal pretreated with a mixture of ginsenosides had shorter duration than in KA-only treated animals. This was supported by Shin et al. work [65], where repeated treatment with ginsenosides mixture before administration of KA has significantly reduced the number of wet dog shakes (WDS), delayed the onset of seizures, and decreased the score of seizures [65]. In another study by Lian et al., it has been demonstrated that the onset of KA-induced seizures was delayed and the score of seizures was decreased in animals pretreated with the partial purified $\mathrm{Rb}$ ginsenosides (Rb extract), significantly [60]. These results indicated that ginseng particularly with the presence of $\mathrm{Rb}$ ginsenosides suppresses KA-induced seizures and has significant anticonvulsant property.

Moreover, pretreatment with $\mathrm{Rb}$ extract before KA administration has reduced the percentage of animal having immunoreactivity for heat-shock protein-72 (HSP-72) [60]. Pretreatment with ginsenosides mixture before KA administration has also suppressed the induction of HSP-70 and has attenuated the neuronal cell death in the CA1 and CA3 regions of the hippocampus [64].

In addition, the treatment with the mixture of ginsenosides has significantly reduced the rise in KA-induced protein oxidation and lipid peroxidation and has significantly attenuated KA-induced glutathione oxidation in the homogenates and mitochondrial fraction of the hippocampus. The effect was more apparent in the mitochondrial fraction than in the homogenate of the hippocampus [65]. Mixture of ginsenosides also attenuated the decrease in manganese-superoxide dismutase-like immunoreactivity (SOD-2-IR) and in superoxide dismutase-2 (SOD-2) protein level in the CA1 and CA3 regions of the hippocampus [65] since Mn-SOD could protect mitochondria from superoxide radicals and the damage induced by KA-induced oxidative stress. This indicated that ginsenosides could prevent KA-induced excitotoxicity by attenuating oxidative stress, particularly in mitochondria, through its antioxidant mechanism.

Mixture of ginsenosides had also significantly attenuated the increase in intramitochondrial $\mathrm{Ca}^{2+}$ level and the decrease in mitochondrial transmembrane potentials in the hippocampus [65]. These findings implied that the mixture of ginsenosides of ginseng could reduce or protect against the excitotoxic effect of KA by attenuating the mitochondrial dysfunction.

Upon KA administration, a significant astrocyte and microglial response was observed and $\mathrm{Rb}$ fraction significantly inhibits the activation of microglia against KA-induced excitotoxicity [26]. $\mathrm{Rb}$ fraction also has been shown to prevent the hippocampal-dependent impairment of spatial cognitive function and hippocampal neurodegeneration [26]. This indicated that $\mathrm{Rb}$ fraction could protect neuron and glial cells against excitotoxicity induced by KA.

In a study on red ginseng extract (RGE), it has been shown that RGE decreased the production of ROS in KA-exposed primary hippocampal neuronal cell culture and inhibited the lipid peroxidation in hippocampal tissue [66]. This indicated that RGE can protect neurons from excitotoxicity through its antioxidant mechanism. Moreover, RGE has also been shown to attenuate the elevation of intracellular $\mathrm{Ca}^{2+}$ level and inhibit neuronal cell loss in KA-induced excitotoxicity in vitro model [66]. Excess accumulation of intracellular $\mathrm{Ca}^{2+}$ can initiate the excitotoxic process, leading to neuronal damage or death. By decreasing the elevation of intracellular $\mathrm{Ca}^{2+}$ level, RGE can protect neurons from neuronal damage or death.

These results suggested that ginseng, particularly with the presence of ginsenosides, displays neuroprotective and antioxidant effects against KA-induced excitotoxicity.

4.2. Uncaria. Uncaria rhynchophylla (Miq.) Jacks (UR) is the dried stems of Uncaria, a genus plant species from Rubiaceae family. UR is a medicinal herb used in the traditional Chinese medicine (TCM) to treat neuronal-associated diseases. Active components found in the extract of UR are the alkaloids of UR, which are rhynchophylline (RP), isorhynchophylline, hirsutine, hirsuteine, corynantheine, corynoxine, and dihydrocorynantheine $[67,68]$. Among these alkaloids, RP and isorhynchophylline are the most widely studied and have been known as neuroprotective compounds [69].

The extract of UR has been shown to possess anticonvulsive effect and free radical scavenging activity in KA-induced epileptic seizures with the inhibition of lipid peroxidation [70,71]. In addition, UR extract has reduced the spread of mossy fibers sprouting, an indicator of recurrent epilepsy [72]. Pretreatment with UR extract before KA administration also has increased the survival of neurons and reduced the epileptiform discharges in the hippocampus [29].

UR also has been reported to exhibit neuroprotective effect against KA-induced neuronal damage, associated with the reduction of microglial activation, neuronal nitric oxide synthase (nNOS), inducible nitric oxide synthase (iNOS), and apoptosis [73] and the attenuation of glial fibrillary acidic protein (GFAP) and S100 calcium-binding protein B (S100B) expression in the hippocampal region [29, 72]. This suggested that UR can prevent hippocampal neuronal death. 
Collectively to date, these findings suggest that UR and RP display neuroprotective and anticonvulsive action in protecting neuronal damage and suppressing KA-induced seizures through multiple signaling pathways and therapeutic targets.

4.3. Tea. Tea is made from leaves and stem of Camellia sinensis plant. This plant is the same plant that is used for making nonfermented (fresh green), semifermented (oolong), fermented (black), and postfermented (Pu-Erh) tea. The chemical composition of tea contains many polyphenolic compounds, called green tea polyphenols. This includes catechins, theaflavins, tannins, and flavonoids. The most major green tea polyphenols are catechins, which include (-)-catechin (EC), (-)-epicatechin gallate (ECG), (-)-epigallocatechin (EGC), and (-)-epigallocatechin gallate (EGCG). Among those catechins, EGCG is the most active polyphenol. EGCG is higher in green tea and is responsible for the green tea effect [74].

In KA-induced seizures, fresh green tea leaf [74] and $\mathrm{Pu}$-Erh tea leaves [75] extracts have attenuated the maximal seizure classes, the behavioral seizure patterns, and lipid peroxidation. While in vitro, these tea leaf extracts have reduced $\mathrm{Ca}^{2+}$ release, ROS production, and lipid peroxidation. These observations implied that fresh green tea leaves and $\mathrm{Pu}-$ Erh tea leaves extract attenuated oxidative stress and have anticonvulsive effect.

In the same studies, fresh green tea leaf and $\mathrm{Pu}$-Erh tea leaf extracts appeared to reduce COX-2 and p38 mitogenactivated protein kinases (MAPK) expression and have reduced PGE2 production KA-induced in vitro PC12 cells [74, 75]. Thus, the tea leaf extract has potential neuroprotective and anticonvulsive effects against excitotoxicity.

4.4. Honey Bee Propolis. Honey bee propolis is a resinous mixture that honey bees collect from a variety of botanical sources. It has been used as a sealant for beehive. The chemical composition of propolis varies with geographic origin depending on the specificity of the local flora, the phenology of the source of plants, and the characteristics of climate [76].

Propolis has been shown to have a wide range of biological activities, including anti-inflammatory [77] and antioxidant [78-80], that are attributed chiefly by the presence of flavonoids $[79,81]$ and caffeic acid phenyl ester (CAPE) [80]. There are studies to suggest the role of flavonoids and CAPE in the antioxidant and anti-inflammatory activities of propolis [79-83].

Propolis has long been used as a folk medicine and protective remedy $[84,85]$. In KA-induced excitotoxicity model, pretreatment with ethanol-extracted propolis before $\mathrm{KA}$ administration has reduced the increase of NO production along with the increase of thiobarbituric acid reactive substances (TBARS) production and the decrease of total antioxidant status (TAS) level [86], indicating that propolis supplementation ameliorated KA-induced oxidative stress.
Furthermore, propolis has been reported to attenuate proinflammatory cytokine marker, the TNF- $\alpha$ level following the administration of KA [84], suggesting that propolis can protect against KA-induced neuronal damage. Propolis also has been shown to restore glutamine synthase activity [86] and ameliorate caspase-3 and NOS activities [84] in the cerebellum, cerebral cortex, and brain stem regions of KAinduced animals. These findings demonstrated that propolis supplementation has beneficial effect against KA-induced neurodegeneration due to its antioxidant, anti-inflammatory, and antiapoptotic properties.

Moreover, propolis has been shown to protect against convulsive behavior induced by $\mathrm{KA}$ in a dose-dependent manner [85]. This suggests that propolis may also possess anticonvulsants property. The pretreatment with propolis also significantly prevented KA-induced neuronal loss in the CA1 and CA3 regions of the hippocampus [85].

4.5. Other Natural Products and Plant Extracts. Many other studies have also tested or reported on the protective effect of KA-induced excitotoxicity in vivo and in vitro models involving other natural products and plant extracts (as summarized in Table 2). Thus, natural products and plant extracts could be potential candidates in the preventive and efficient treatment of excitotoxicity-associated neurodegeneration diseases.

Collectively, these findings suggest that the natural products and plant extracts appear to have potential neuroprotective effect against KA-induced excitotoxicity through various mechanisms, primarily through their antioxidant, antiinflammatory, and anticonvulsive activities. This signifies the therapeutic merits of the natural products and plant extracts as neuroprotective agents. Further studies are needed to determine the other potentials and various mechanisms of actions of these natural products and plant extracts guard against KA-induced excitotoxicity.

\section{Conclusion}

Natural products and plant extracts appear to offer potential beneficial effects on the CNS, particularly their neuroprotective effect against excitotoxicity. In addition, natural products and plant extracts provide promising avenue for further research to guard against development and progression of acute and chronic neurodegeneration. Further work can aim at targeting simultaneous pathways that underlie the various mechanisms involved in order to expand the therapeutic yields for various neurodegeneration diseases.

\section{Conflict of Interests}

There is no conflict of interests. 


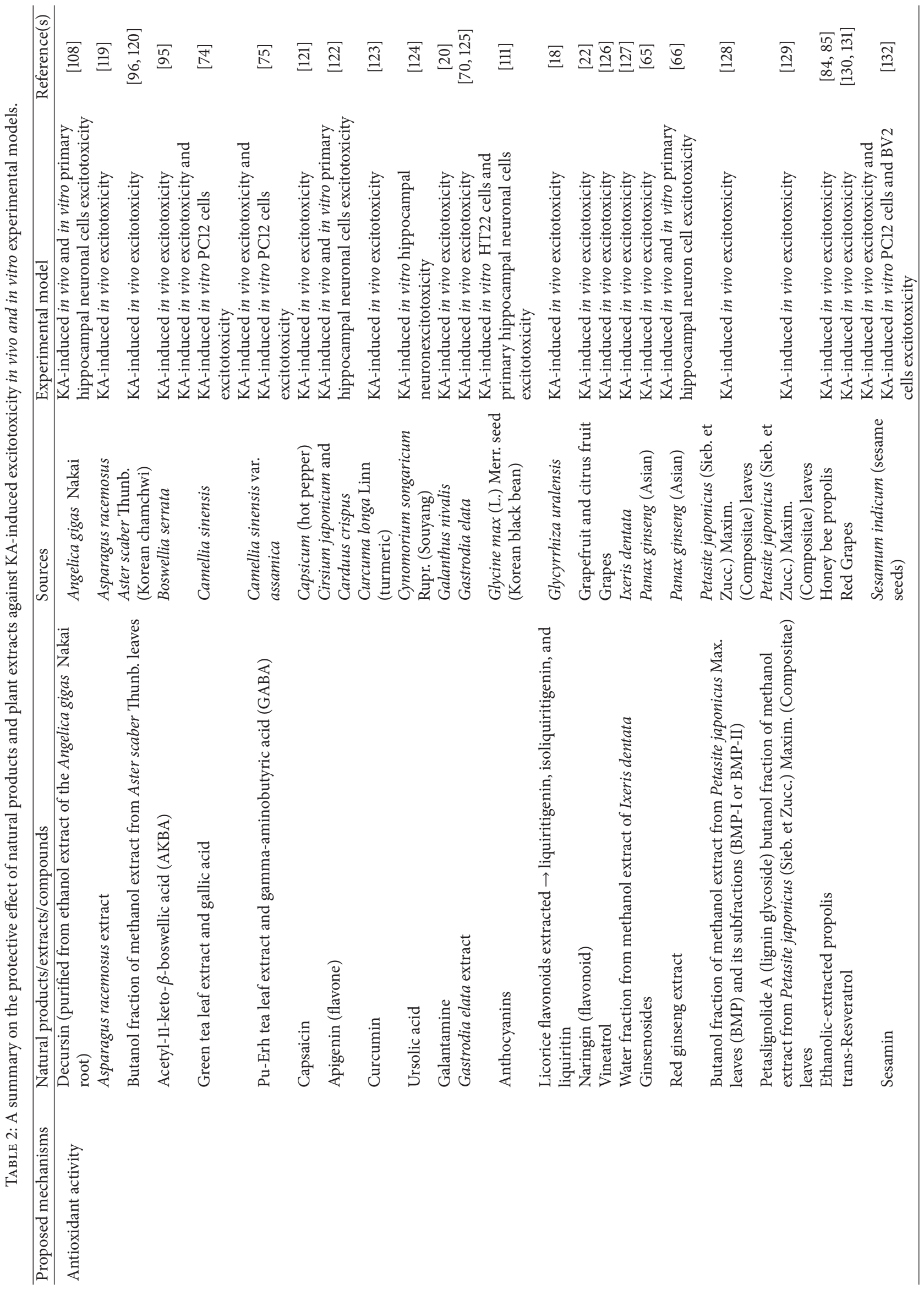




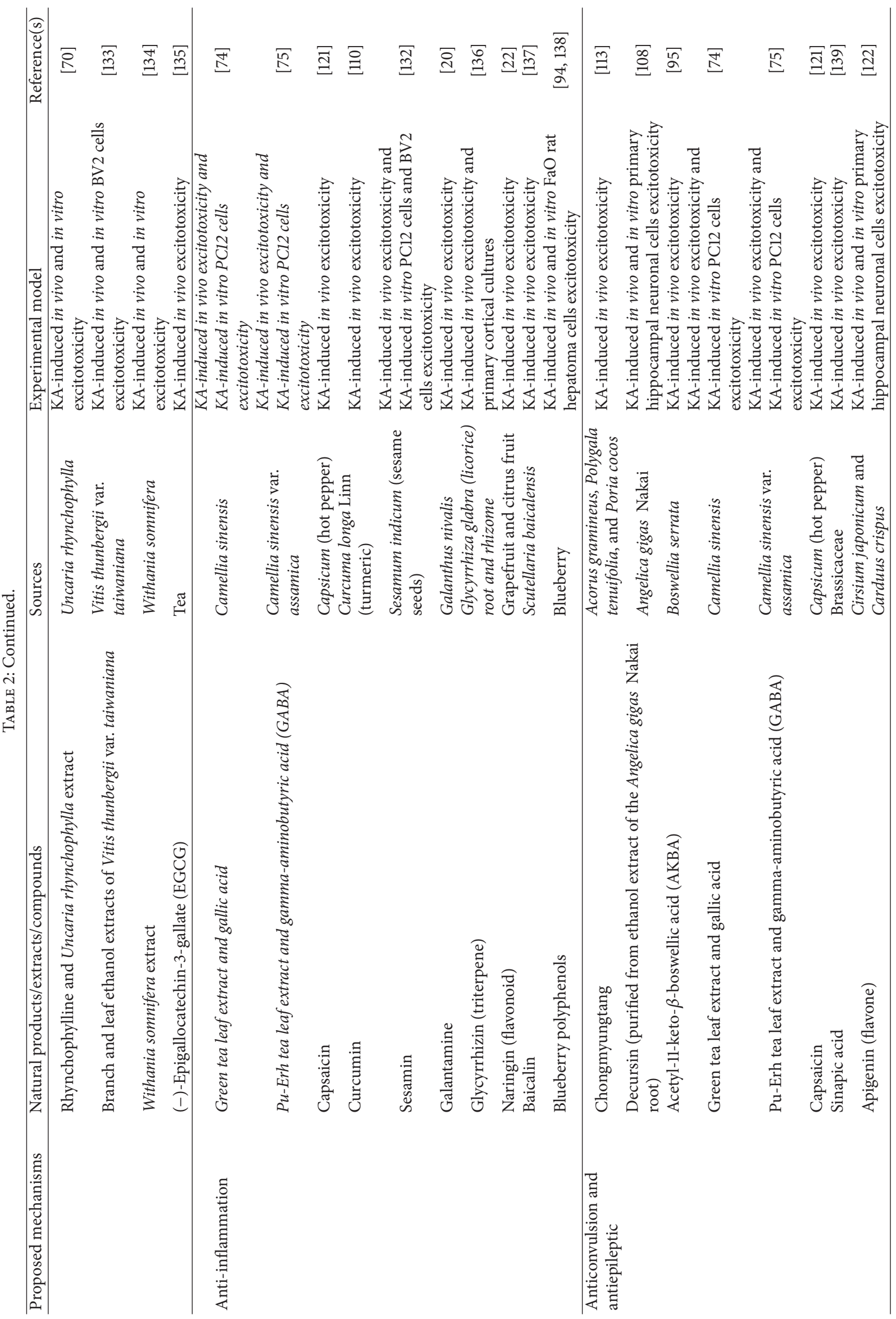




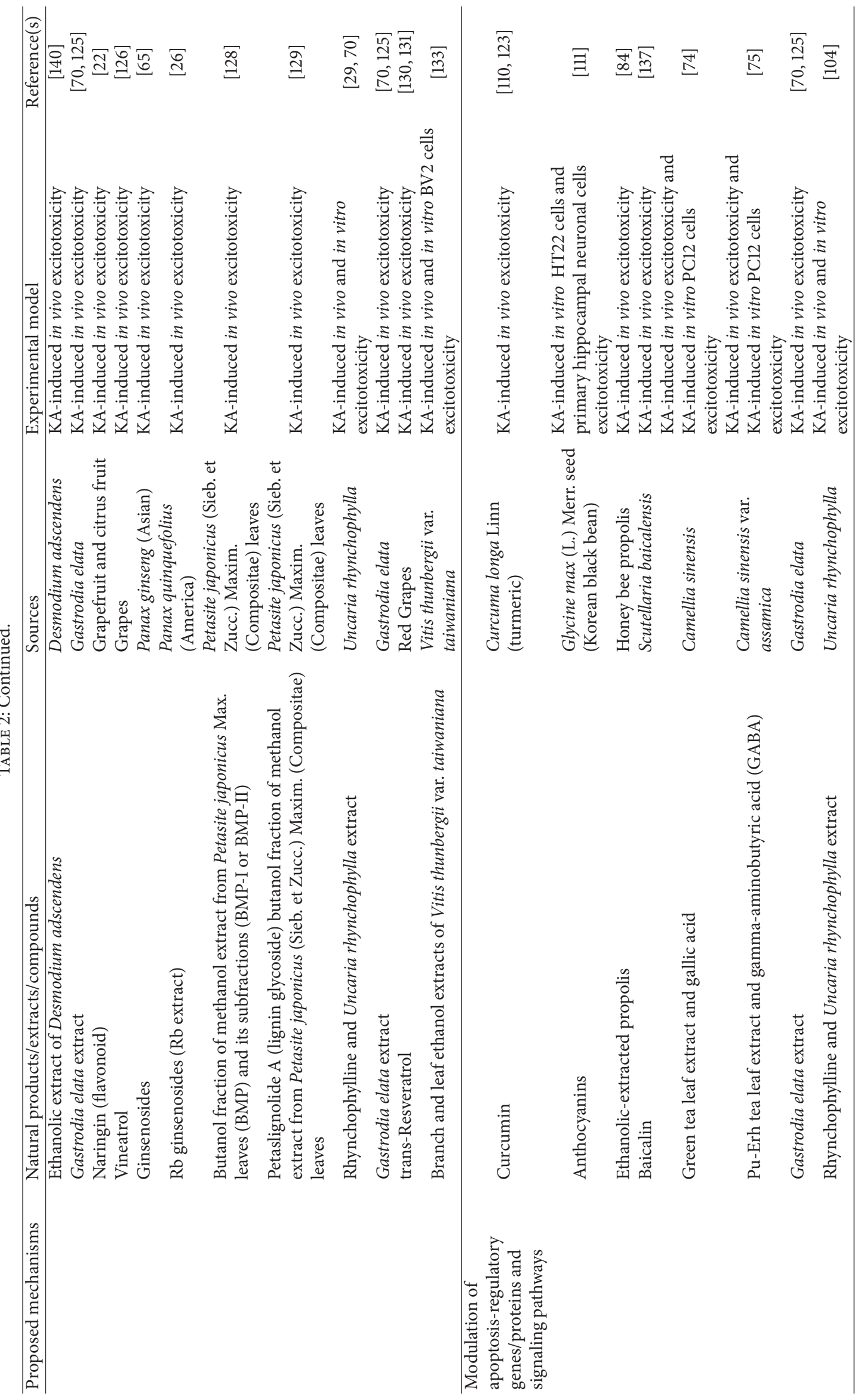




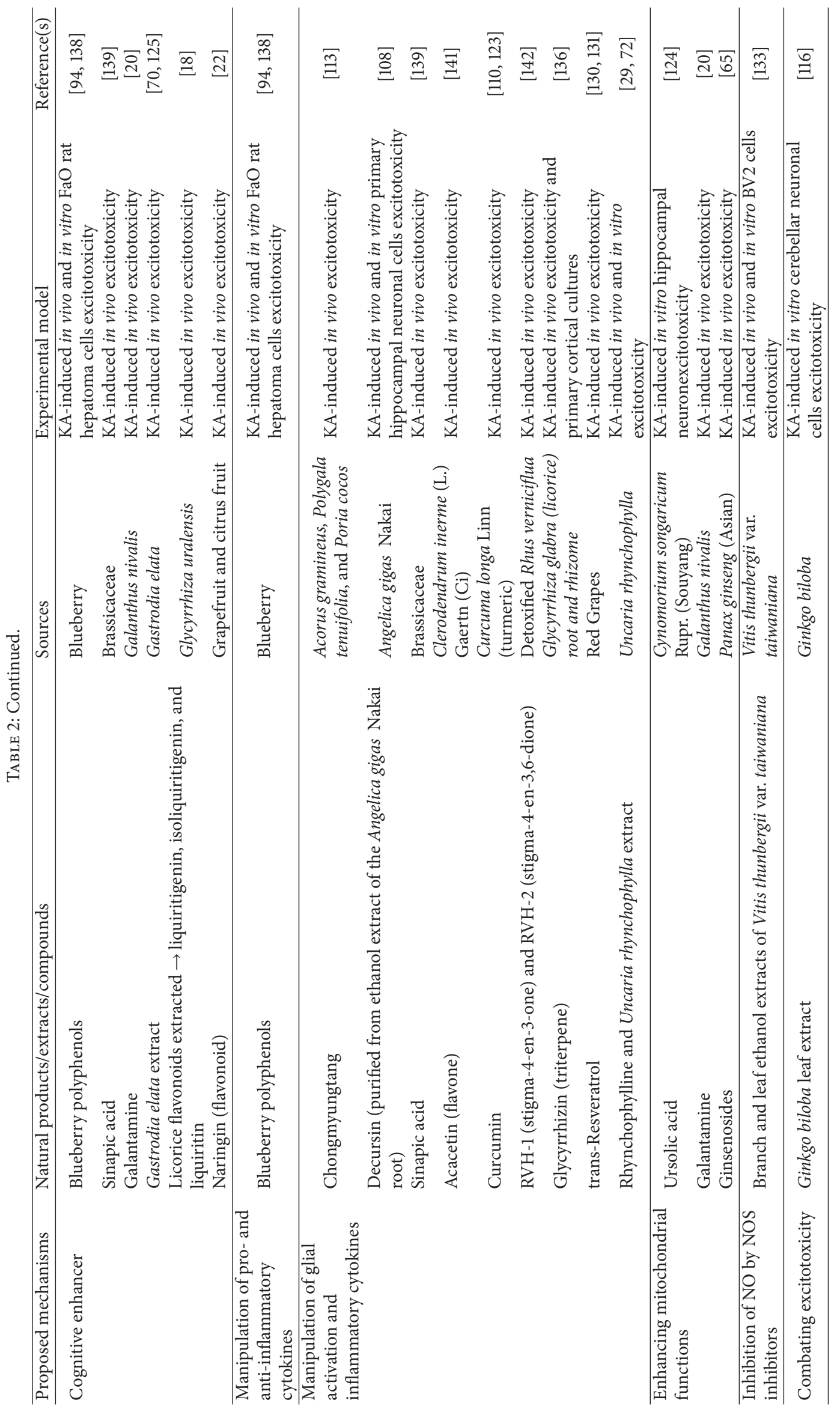




\section{Acknowledgments}

The authors would like to acknowledge Universiti Sains Malaysia for Research University Grant no. 1001/PPSP/811203 and USM Global Fellowship to the first author.

\section{References}

[1] A. Doble, "The role of excitotoxicity in neurodegenerative disease: implications for therapy," Pharmacology and Therapeutics, vol. 81, no. 3, pp. 163-221, 1999.

[2] J. W. Olney, "Brain lesions, obesity, and other disturbances in mice treated with monosodium glutamate," Science, vol. 164, no. 3880, pp. 719-721, 1969.

[3] C. E. Herron, R. A. J. Lester, E. J. Coan, and G. L. Collingridge, "Frequency-dependent involvement of NMDA receptors in the hippocampus: a novel synaptic mechanism," Nature, vol. 322, no. 6076, pp. 265-268, 1986.

[4] N. M. Zahr, E. L. F. Crawford, O. Hsu et al., "In vivo glutamate decline associated with kainic acid-induced status epilepticus," Brain Research, vol. 1300, pp. 65-78, 2009.

[5] Z. I. Bashir, Z. A. Bortolotto, C. H. Davies et al., "Induction of LTP in the hippocampus needs synaptic activation of glutamate metabotropic receptors," Nature, vol. 363, no. 6427, pp. 347-350, 1993.

[6] D. G. Rainnie, K. H. Holmes, and P. Shinnick-Gallagher, "Activation of postsynaptic metabotropic glutamate receptors by trans-ACPD hyperpolarizes neurons of the basolateral amygdala," Journal of Neuroscience, vol. 14, part 2, no. 11, pp. 72087220, 1994.

[7] W. Löscher, H. Lehmann, B. Behl, and et al, "A new pyrrolylquinoxalinedione series of non-NMDA glutamate receptor antagonists: pharmacological characterization and comparison with NBQX and valproate in the kindling model of epilepsy," European Journal of Neuroscience, vol. 11, no. 1, pp. 250-262, 1999.

[8] D. G. Trist, "Excitatory amino acid agonists and antagonists: pharmacology and therapeutic applications," Pharmaceutica Acta Helvetiae, vol. 74, no. 2-3, pp. 221-229, 2000.

[9] G. Sperk, "Kainic acid seizures in the rat," Progress in Neurobiology, vol. 42, no. 1, pp. 1-32, 1994.

[10] D.-H. Youn and M. Randić, "Modulation of excitatory synaptic transmission in the spinal substantia gelatinosa of mice deficient in the kainate receptor GluR5 and/or GluR6 subunit," Journal of Physiology, vol. 555, no. 3, pp. 683-698, 2004.

[11] S. L. Campbell, S. S. Mathew, and J. J. Hablitz, "Pre- and postsynaptic effects of kainate on layer II/III pyramidal cells in rat neocortex," Neuropharmacology, vol. 53, no. 1, pp. 37-47, 2007.

[12] E. W. Lothman and R. C. Collins, "Kainic acid induced limbic seizures: metabolic, behavioral, electroencephalographic and neuropathological correlates," Brain Research, vol. 218, no. 1-2, pp. 299-318, 1981.

[13] G. Sperk, H. Lassmann, H. Baran, F. Seitelberger, and O. Hornykiewicz, "Kainic acid-induced seizures: dose-relationship of behavioural neurochemical and histopathological changes," Brain Research, vol. 338, no. 2, pp. 289-295, 1985.

[14] X. Zhang, D. L. Gelowitz, C. T. Lai, A. A. Boulton, and P. H. $\mathrm{Yu}$, "Gradation of kainic acid-induced rat limbic seizures and expression of hippocampal heat shock protein-70," European Journal of Neuroscience, vol. 9, no. 4, pp. 760-769, 1997.
[15] Y. Ben-Ari, "Limbic seizure and brain damage produced by kainic acid: mechanisms and relevance to human temporal lobe epilepsy," Neuroscience, vol. 14, no. 2, pp. 375-403, 1985.

[16] A. Mikulecká, P. Kršek, and P. Mareš, "Nonconvulsive kainic acid-induced seizures elicit age-dependent impairment of memory for the elevated plus-maze," Epilepsy \& Behavior, vol. 1, no. 6, pp. 418-426, 2000.

[17] P. Miltiadous, G. Kouroupi, A. Stamatakis, P. N. Koutsoudaki, R. Matsas, and F. Stylianopoulou, "Subventricular zone-derived neural stem cell grafts protect against hippocampal degeneration and restore cognitive function in the mouse following intrahippocampal kainic acid administration," Stem Cells Translational Medicine, vol. 2, no. 3, pp. 185-198, 2013.

[18] L.-H. Zeng, H.-D. Zhang, C.-J. Xu et al., "Neuroprotective effects of flavonoids extracted from licorice on kainate-induced seizure in mice through their antioxidant properties," Journal of Zhejiang University. Science B, vol. 14, no. 11, pp. 1004-1012, 2013.

[19] M. J. Gayoso, C. Primo, A. Al-Majdalawi, J. M. Fernandez, M. Garrosa, and C. Iñiguez, "Brain lesions and water-maze learning deficits after systemic administration of kainic acid to adult rats," Brain Research, vol. 653, no. 1-2, pp. 92-100, 1994.

[20] A. Kumar, A. Prakash, and D. Pahwa, "Galantamine potentiates the protective effect of rofecoxib and caffeic acid against intrahippocampal Kainic acid-induced cognitive dysfunction in rat," Brain Research Bulletin, vol. 85, no. 3-4, pp. 158-168, 2011.

[21] C. E. Stafstrom, A. Chronopoulos, S. Thurber, J. L. Thompson, and G. L. Holmes, "Age-dependent cognitive and behavioral deficits after kainic acid seizures," Epilepsia, vol. 34, no. 3, pp. 420-432, 1993.

[22] M. Golechha, U. Chaudhry, J. Bhatia, D. Saluja, and D. S. Arya, "Naringin protects against kainic acid-induced status epilepticus in rats: evidence for an antioxidant, anti-inflammatory and neuroprotective intervention," Biological \& Pharmaceutical Bulletin, vol. 34, no. 3, pp. 360-365, 2011.

[23] M. R. Gluck, E. Jayatilleke, S. Shaw, A. J. Rowan, and V. Haroutunian, "CNS oxidative stress associated with the kainic acid rodent model of experimental epilepsy," Epilepsy Research, vol. 39, no. 1, pp. 63-71, 2000.

[24] A. J. Bruce and M. Baudry, "Oxygen free radicals in rat limbic structures after kainate-induced seizures," Free Radical Biology and Medicine, vol. 18, no. 6, pp. 993-1002, 1995.

[25] H.-C. Kim, W.-K. Jhoo, G. Bing et al., "Phenidone prevents kainate-induced neurotoxicity via antioxidant mechanisms," Brain Research, vol. 874, no. 1, pp. 15-23, 2000.

[26] K. Xu, Y. Zhang, Y. Wang et al., "Ginseng Rb fraction protects glia, neurons and cognitive function in a rat model of neurodegeneration," PLoS ONE, vol. 9, no. 6, Article ID e101077, 2014.

[27] I.-H. Cho, J. Hong, E. C. Suh et al., "Role of microglial IKK $\beta$ in kainic acid-induced hippocampal neuronal cell death," Brain, vol. 131, no. 11, pp. 3019-3033, 2008.

[28] J. Hong, I.-H. Cho, K. I. Kwak et al., "Microglial toll-like receptor 2 contributes to kainic acid-induced glial activation and hippocampal neuronal cell death," The Journal of Biological Chemistry, vol. 285, no. 50, pp. 39447-39457, 2010.

[29] Y.-W. Lin and C.-L. Hsieh, "Oral Uncaria rhynchophylla (UR) reduces kainic acid-induced epileptic seizures and neuronal death accompanied by attenuating glial cell proliferation and S100B proteins in rats," Journal of Ethnopharmacology, vol. 135, no. 2, pp. 313-320, 2011.

[30] Z. Chen, R.-S. Duan, H. C. Quezada et al., "Increased microglial activation and astrogliosis after intranasal administration of 
kainic acid in C57BL/6 mice," Journal of Neurobiology, vol. 62, no. 2, pp. 207-218, 2005.

[31] T. Ravizza, M. Rizzi, C. Perego et al., "Inflammatory response and glia activation in developing rat hippocampus after status epilepticus," Epilepsia, vol. 46, supplement 5, pp. 113-117, 2005.

[32] X.-M. Zhang, R.-S. Duan, Z. Chen et al., "IL-18 deficiency aggravates kainic acid-induced hippocampal neurodegeneration in C57BL/6 mice due to an overcompensation by IL-12," Experimental Neurology, vol. 205, no. 1, pp. 64-73, 2007.

[33] M.-O. Lu, X.-M. Zhang, E. Mix et al., "TNF-alpha receptor 1 deficiency enhances kainic acid-induced hippocampal injury in mice," Journal of Neuroscience Research, vol. 86, no. 7, pp. 16081614, 2008.

[34] A.-L. Sokka, N. Putkonen, G. Mudo et al., "Endoplasmic reticulum stress inhibition protects against excitotoxic neuronal injury in the rat brain," The Journal of Neuroscience, vol. 27, no. 4, pp. 901-908, 2007.

[35] J. F. Torres-Peraza, T. Engel, R. Martín-Ibáñez et al., "Protective neuronal induction of ATF5 in endoplasmic reticulum stress induced by status epilepticus," Brain, vol. 136, part 4, pp. 11611176, 2013.

[36] Y.-C. Chuang, A. Y. W. Chang, J.-W. Lin, S.-P. Hsu, and S. H. H. Chan, "Mitochondrial dysfunction and ultrastructural damage in the hippocampus during kainic acid-induced status epilepticus in the rat," Epilepsia, vol. 45, no. 10, pp. 1202-1209, 2004.

[37] J. S. Kim, R. W. Heo, H. Kim et al., "Salubrinal, ER stress inhibitor, attenuates kainic acid-induced hippocampal cell death," Journal of Neural Transmission, vol. 121, no. 10, pp. 12331243, 2014.

[38] G. M. McKhann II, H. J. Wenzel, C. A. Robbins, A. A. Sosunov, and P. A. Schwartzkroin, "Mouse strain differences in kainic acid sensitivity, seizure behavior, mortality, and hippocampal pathology," Neuroscience, vol. 122, no. 2, pp. 551-561, 2003.

[39] S. Ratté and J.-C. Lacaille, "Selective degeneration and synaptic reorganization of hippocampal interneurons in a chronic model of temporal lobe epilepsy," Advances in Neurology, vol. 97, pp. 69-76, 2006.

[40] L.-H. Zeng, N. R. Rensing, and M. Wong, "The mammalian target of rapamycin signaling pathway mediates epileptogenesis in a model of temporal lobe epilepsy," Journal of Neuroscience, vol. 29, no. 21, pp. 6964-6972, 2009.

[41] S. J. Royle, F. C. Collins, H. Rupniak, J. C. Barnes, and R. Anderson, "Behavioural analysis and susceptibility to CNS injury of four inbred strains of mice," Brain Research, vol. 816, no. 2, pp. 337-349, 1999.

[42] Y. Ben-Ari and R. Cossart, "Kainate, a double agent that generates seizures: two decades of progress," Trends in Neurosciences, vol. 23, no. 11, pp. 580-587, 2000.

[43] N. Nakao, E. M. Grasbon-Frodl, H. Widner, and P. Brundin, "Antioxidant treatment protects striatal neurons against excitotoxic insults," Neuroscience, vol. 73, no. 1, pp. 185-200, 1996.

[44] A. Melo, L. Monteiro, R. M. F. Lima, D. M. de Oliveira, M. D. de Cerqueira, and R. S. El-Bachá, "Oxidative stress in neurodegenerative diseases: mechanisms and therapeutic perspectives," Oxidative Medicine and Cellular Longevity, vol. 2011, Article ID 467180, 14 pages, 2011.

[45] R. A. Floyd, "Antioxidants, oxidative stress, and degenerative neurological disorders," Proceedings of the Society for Experimental Biology and Medicine, vol. 222, no. 3, pp. 236-245, 1999.
[46] Q. Wang, S. Yu, A. Simonyi, G. Y. Sun, and A. Y. Sun, "Kainic acid-mediated excitotoxicity as a model for neurodegeneration," Molecular Neurobiology, vol. 31, no. 1-3, pp. 3-16, 2005.

[47] T. L. Sandhya, W. Y. Ong, L. A. Horrocks, and A. A. Farooqui, "A light and electron microscopic study of cytoplasmic phospholipase $\mathrm{A}_{2}$ and cyclooxygenase- 2 in the hippocampus after kainate lesions," Brain Research, vol. 788, no. 1-2, pp. 223-231, 1998.

[48] W. Y. Ong, L. J. Garey, and K. K. Tan, "An immunocytochemical study of calpain II in the hippocampus of rats injected with kainate," Experimental Brain Research, vol. 113, no. 1, pp. 117-129, 1997.

[49] T. C. Frank-Cannon, L. T. Alto, F. E. McAlpine, and M. G. Tansey, "Does neuroinflammation fan the flame in neurodegenerative diseases?" Molecular Neurodegeneration, vol. 4, no. 1, article 47, 2009.

[50] W. J. Streit, R. E. Mrak, and W. S. T. Griffin, "Microglia and neuroinflammation: a pathological perspective," Journal of Neuroinflammation, vol. 1, no. 1, article 14, 2004.

[51] M. E. Lull and M. L. Block, "Microglial activation and chronic neurodegeneration," Neurotherapeutics, vol. 7, no. 4, pp. 354$365,2010$.

[52] M. L. Block and J.-S. Hong, "Microglia and inflammationmediated neurodegeneration: multiple triggers with a common mechanism," Progress in Neurobiology, vol. 76, no. 2, pp. 77-98, 2005.

[53] H.-M. Gao, H. Zhou, and J.-S. Hong, "Oxidative stress, neuroinflammation, and neurodegeneration," in in Neuroinflammation and Neurodegeneration, P. K. Peterson and and M. Toborek, Eds., pp. 81-104, Springer, New York, NY, USA, 2014.

[54] X.-Y. Zheng, H.-L. Zhang, Q. Luo, and J. Zhu, "Kainic acidinduced neurodegenerative model: potentials and limitations," Journal of Biomedicine and Biotechnology, vol. 2011, Article ID 457079, 10 pages, 2011.

[55] X.-M. Zhang and J. Zhu, "Kainic acid-induced neurotoxicity: targeting glial responses and glia-derived cytokines," Current Neuropharmacology, vol. 9, no. 2, pp. 388-398, 2011.

[56] K. L. Gilliams-Francis, A. A. Quaye, and J. R. Naegele, "PARP cleavage, DNA fragmentation, and pyknosis during excitotoxin-induced neuronal death," Experimental Neurology, vol. 184, no. 1, pp. 359-372, 2003.

[57] M. V. Frantseva, J. L. P. Velazquez, P. A. Hwang, and P. L. Carlen, "Free radical production correlates with cell death in an in vitro model of epilepsy," European Journal of Neuroscience, vol. 12, no. 4, pp. 1431-1439, 2000.

[58] A. S. Attele, J. A. Wu, and C.-S. Yuan, "Ginseng pharmacology: multiple constituents and multiple actions," Biochemical Pharmacology, vol. 58, no. 11, pp. 1685-1693, 1999.

[59] M. A. Kuhn and W. David, Herbal Therapy and Supplements: A Scientific and Traditional Approach, Lippincott Williams and Wilkins, New York, NY, USA, 2000.

[60] X.-Y. Lian, Z.-Z. Zhang, and J. L. Stringer, "Anticonvulsant activity of ginseng on seizures induced by chemical convulsants," Epilepsia, vol. 46, no. 1, pp. 15-22, 2005.

[61] S.-Y. Nah, D.-H. Kim, and H. Rhim, "Ginsenosides: are any of them candidates for drugs acting on the central nervous system?” CNS Drug Reviews, vol. 13, no. 4, pp. 381-404, 2007.

[62] E. Tachikawa, K. Kudo, K. Harada et al., "Effects of ginseng saponins on responses induced by various receptor stimuli," European Journal of Pharmacology, vol. 369, no. 1, pp. 23-32, 1999. 
[63] D. Tsang, H. W. Yeung, W. W. Tso, and H. Peck, "Ginseng saponins: influence on neurotransmitter uptake in rat brain synaptosomes," Planta Medica, vol. 3, pp. 221-224, 1985.

[64] J.-H. Lee, S.-R. Kim, C.-S. Bae, D. Kim, H.-N. Hong, and S.Y. Nah, "Protective effect of ginsenosides, active ingredients of Panax ginseng, on kainic acid-induced neurotoxicity in rat hippocampus," Neuroscience Letters, vol. 325, no. 2, pp. 129-133, 2002.

[65] E.-J. Shin, J. H. Jeong, A.-Y. Kim et al., "Protection against kainate neurotoxicity by ginsenosides: attenuation of convulsive behavior, mitochondrial dysfunction, and oxidative stress," Journal of Neuroscience Research, vol. 87, no. 3, pp. 710-722, 2009.

[66] J.-Y. Han, S.-Y. Ahn, E.-H. Oh et al., "Red ginseng extract attenuates kainate-induced excitotoxicity by antioxidative effects," Evidence-Based Complementary and Alternative Medicine, vol. 2012, Article ID 479016, 10 pages, 2012.

[67] J.-S. Shi, J.-X. Yu, X.-P. Chen, and R.-X. Xu, "Pharmacological actions of Uncaria alkaloids, rhynchophylline and isorhynchophylline," Acta Pharmacologica Sinica, vol. 24, no. 2, pp. 97101, 2003.

[68] Y.-F. Xian, Z.-X. Lin, Q.-Q. Mao et al., "Bioassay-guided isolation of neuroprotective compounds from Uncaria rhynchophylla against beta-amyloid-induced neurotoxicity," Evidence-Based Complementary and Alternative Medicine, vol. 2012, Article ID 802625, 8 pages, 2012.

[69] T.-H. Kang, Y. Murakami, K. Matsumoto et al., "Rhynchophylline and isorhynchophylline inhibit NMDA receptors expressed in Xenopus oocytes," European Journal of Pharmacology, vol. 455, no. 1, pp. 27-34, 2002.

[70] C.-L. Hsieh, N.-Y. Tang, S.-Y. Chiang, C.-T. Hsieh, and J.-G. Lin, "Anticonvulsive and free radical scavenging actions of two herbs, Uncaria rhynchophylla (Miq) Jack and Gastrodia elata Bl., in kainic acid-treated rats," Life Sciences, vol. 65, no. 20, pp. 20712082, 1999.

[71] C.-L. Hsieh, M.-F. Chen, T.-C. Li et al., "Anticonvulsant effect of Uncaria rhynchophylla (Miq) Jack. in rats with kainic acidinduced epileptic seizure," The American Journal of Chinese Medicine, vol. 27, no. 2, pp. 257-264, 1999.

[72] C.-L. Hsieh, C.-H. Liu, Y.-W. Lin, N.-Y. Tang, and H.-J. Liu, "Neuroprotective effect of Uncaria rhynchophylla in Kainic acid-induced epileptic seizures by modulating hippocampal mossy fiber sprouting, neuron survival, astrocyte proliferation, and S100b expression," Evidence-Based Complementary and Alternative Medicine, vol. 2012, Article ID 194790, 11 pages, 2012.

[73] N.-Y. Tang, C.-H. Liu, S.-Y. Su et al., "Uncaria rhynchophylla (Miq) Jack plays a role in neuronal protection in kainic acidtreated rats," American Journal of Chinese Medicine, vol. 38, no. 2, pp. 251-263, 2010.

[74] H.-L. Huang, C.-C. Lin, K.-C. G. Jeng et al., "Fresh green tea and gallic acid ameliorate oxidative stress in kainic acid-induced status epilepticus," Journal of Agricultural and Food Chemistry, vol. 60, no. 9, pp. 2328-2336, 2012.

[75] C.-W. Hou, "Pu-Erh tea and GABA attenuates oxidative stress in kainic acid-induced status epilepticus," Journal of Biomedical Science, vol. 18, article 75, 2011.

[76] É. W. Teixeira, D. Message, G. Negri, A. Salatino, and P. C. Stringheta, "Seasonal variation, chemical composition and antioxidant activity of brazilian propolis samples," EvidenceBased Complementary and Alternative Medicine, vol. 7, no. 3, pp. 307-315, 2010.
[77] L. Wang, S. Mineshita, and I. Ga, "Antiinflamatory effects of propolis," Japanese Journal of Pharmacological Therapeutics, vol. 24, pp. 223-226, 1993.

[78] P. Basnet, T. Matsuno, and R. Neidlein, "Potent free radical scavenging activity of propol isolated from Brazilian propolis," Zeitschrift fur Naturforschung C, vol. 52, no. 11-12, pp. 828-833, 1997.

[79] M. I. Isla, M. I. Nieva Moreno, A. R. Sampietro, and M. A. Vattuone, "Antioxidant activity of Argentine propolis extracts," Journal of Ethnopharmacology, vol. 76, no. 2, pp. 165-170, 2001.

[80] K. Natarajan, S. Singh, T. R. Burke Jr., D. Grunberger, and B. B. Aggarwal, "Caffeic acid phenethyl ester is a potent and specific inhibitor of activation of nuclear transcription factor NF- $\kappa \mathrm{B}$," Proceedings of the National Academy of Sciences of the United States of America, vol. 93, no. 17, pp. 9090-9095, 1996.

[81] G. Coneac, E. Gafiţanu, D. Hădărugă et al., "Flavonoid contents of propolis from the West Side of Romania and correlation with the antioxidant activity," Chemical Bulletin "Politehnica" University Timişoara, vol. 53, no. 67, p. 5, 2008.

[82] F. Borrelli, P. Maffia, L. Pinto et al., "Phytochemical compounds involved in the anti-inflammatory effect of propolis extract," Fitoterapia, vol. 73, supplement 1, pp. S53-S63, 2002.

[83] A. Russo, R. Longo, and A. Vanella, "Antioxidant activity of propolis: role of caffeic acid phenethyl ester and galangin," Fitoterapia, vol. 73, supplement 1, pp. S21-S29, 2002.

[84] M. Swamy, D. Suhaili, K. N. S. Sirajudeen, Z. Mustapha, and C. Govindasamy, "Propolis ameliorates tumor nerosis factor$\alpha$, nitric oxide levels, caspase- 3 and nitric oxide synthase activities in kainic acid mediated excitotoxicity in rat brain," African Journal of Traditional, Complementary and Alternative Medicines, vol. 11, no. 5, pp. 48-53, 2014.

[85] Y.-S. Kwon, D.-H. Park, E.-J. Shin et al., "Antioxidant propolis attenuates kainate-induced neurotoxicity via adenosine $A_{1}$ receptor modulation in the rat," Neuroscience Letters, vol. 355, no. 3, pp. 231-235, 2004.

[86] M. Swamy, W. Norlina, W. Azman et al., "Restoration of glutamine synthetase activity, nitric oxide levels and amelioration of oxidative stress by propolis in kainic acid mediated excitotoxicity," African Journal of Traditional, Complementary and Alternative Medicines, vol. 11, no. 2, pp. 458-463, 2014.

[87] H. Manev, T. Uz, and T. Qu, "5-Lipoxygenase and cyclooxygenase mRNA expression in rat hippocampus: early response to glutamate receptor activation by kainate," Experimental Gerontology, vol. 35, no. 9-10, pp. 1201-1209, 2000.

[88] E. J. Kim, J. E. Lee, K. J. Kwon, S. H. Lee, C.-H. Moon, and E. J. Baik, "Differential roles of cyclooxygenase isoforms after kainic acid-induced prostaglandin E2 production and neurodegeneration in cortical and hippocampal cell cultures," Brain Research, vol. 908, no. 1, pp. 1-9, 2001.

[89] H. Baran, K. Vass, H. Lassmann, and O. Hornykiewicz, "The cyclooxygenase and lipoxygenase inhibitor BW755C protects rats against kainic acid-induced seizures and neurotoxicity," Brain Research, vol. 646, no. 2, pp. 201-206, 1994.

[90] L. Minutoli, H. Marini, M. Rinaldi et al., "A dual inhibitor of cyclooxygenase and 5-lipoxygenase protects against kainic acid-induced brain injury," NeuroMolecular Medicine, vol. 17, no. 2, pp. 192-201, 2015.

[91] O. L. Gobbo and S. M. O’Mara, "Post-treatment, but not pre-treatment, with the selective cyclooxygenase-2 inhibitor celecoxib markedly enhances functional recovery from kainic acid-induced neurodegeneration," Neuroscience, vol. 125, no. 2, pp. 317-327, 2004. 
[92] J. W. Phillis, L. A. Horrocks, and A. A. Farooqui, "Cyclooxygenases, lipoxygenases, and epoxygenases in CNS: their role and involvement in neurological disorders," Brain Research Reviews, vol. 52, no. 2, pp. 201-243, 2006.

[93] M. Oprica, C. Eriksson, and M. Schultzberg, "Inflammatory mechanisms associated with brain damage induced by kainic acid with special reference to the interleukin-1 system," Journal of Cellular and Molecular Medicine, vol. 7, no. 2, pp. 127-140, 2003.

[94] B. Shukitt-Hale, F. C. Lau, A. N. Carey et al., "Blueberry polyphenols attenuate kainic acid-induced decrements in cognition and alter inflammatory gene expression in rat hippocampus," Nutritional Neuroscience, vol. 11, no. 4, pp. 172-182, 2008.

[95] M. Bishnoi, C. S. Patil, A. Kumar, and S. K. Kulkarni, "Coadministration of acetyl-11-keto- $\beta$-boswellic acid, a specific 5lipoxygenase inhibitor, potentiates the protective effect of COX2 inhibitors in kainic acid-induced neurotoxicity in mice," Pharmacology, vol. 79, no. 1, pp. 34-41, 2007.

[96] D.-E. Sok, S. H. Oh, Y.-B. Kim, and M. R. Kim, "Neuroprotective effect of rough aster butanol fraction against oxidative stress in the brain of mice challenged with kainic acid," Journal of Agricultural and Food Chemistry, vol. 51, no. 16, pp. 4570-4575, 2003.

[97] E. J. Kim, R. Won, J.-H. Sohn et al., "Anti-oxidant effect of ascorbic and dehydroascorbic acids in hippocampal slice culture," Biochemical and Biophysical Research Communications, vol.366, no. 1, pp. 8-14, 2008.

[98] H.-C. Kim, W.-K. Jhoo, W.-K. Kim et al., "An immunocytochemical study of mitochondrial manganese-superoxide dismutase in the rat hippocampus after kainate administration," Neuroscience Letters, vol. 281, no. 1, pp. 65-68, 2000.

[99] T. B. Mojarad and M. Roghani, "The anticonvulsant and antioxidant effects of berberine in kainate-induced temporal lobe epilepsy in rats," Basic and Clinical Neuroscience, vol. 5, no. 2, pp. 124-130, 2014.

[100] E.-J. Shin, K. H. Ko, W.-K. Kim et al., "Role of glutathione peroxidase in the ontogeny of hippocampal oxidative stress and kainate seizure sensitivity in the genetically epilepsy-prone rats," Neurochemistry International, vol. 52, no. 6, pp. 1134-1147, 2008.

[101] M. Floreani, S. D. Skaper, L. Facci, M. Lipartiti, and P. Giusti, "Melatonin maintains glutathione homeostasis in kainic acidexposed rat brain tissues," The FASEB Journal, vol. 11, no. 14, pp. 1309-1315, 1997.

[102] E.-J. Shin, J. H. Jeong, G. Bing et al., "Kainate-induced mitochondrial oxidative stress contributes to hippocampal degeneration in senescence-accelerated mice," Cellular Signalling, vol. 20, no. 4, pp. 645-658, 2008.

[103] J.-K. Lee, J.-S. Won, A. K. Singh, and I. Singh, "Statin inhibits kainic acid-induced seizure and associated inflammation and hippocampal cell death," Neuroscience Letters, vol. 440, no. 3, pp. 260-264, 2008.

[104] H.-C. Hsu, N.-Y. Tang, C.-H. Liu, and C.-L. Hsieh, "Antiepileptic effect of Uncaria rhynchophylla and Rhynchophylline involved in the initiation of c-jun N-terminal kinase phosphorylation of MAPK signal pathways in acute seizures of kainic acid-treated rats," Evidence-Based Complementary and Alternative Medicine, vol. 2013, Article ID 961289, 9 pages, 2013.

[105] T.-T. Tzeng, H.-J. Tsay, L. Chang et al., "Caspase 3 involves in neuroplasticity, microglial activation and neurogenesis in the mice hippocampus after intracerebral injection of kainic acid," Journal of Biomedical Science, vol. 20, no. 1, article 90, 2013.
[106] J. Sun, C. Xie, W. Liu et al., "The effects of simvastatin on hippocampal caspase- 3 and Bcl-2 expression following kainateinduced seizures in rats," International Journal of Molecular Medicine, vol. 30, no. 4, pp. 739-746, 2012.

[107] A. Kondratyev and K. Gale, "Intracerebral injection of caspase3 inhibitor prevents neuronal apoptosis after kainic acid-evoked status epilepticus," Molecular Brain Research, vol. 75, no. 2, pp. 216-224, 2000.

[108] J.-K. Lee, J. W. Jeong, T. Jang et al., "Decursin attenuates kainic acid-induced seizures in mice," NeuroReport, vol. 25, no. 16, pp. 1243-1249, 2014.

[109] J.-K. Lee, S.-S. Choi, H.-K. Lee, K.-J. Han, E.-J. Han, and H.-W. Suh, "Effects of ginsenoside Rd and decursinol on the neurotoxic responses induced by kainic acid in mice," Planta Medica, vol. 69, no. 3, pp. 230-234, 2003.

[110] H. J. Shin, J. Y. Lee, E. Son et al., "Curcumin attenuates the kainic acid-induced hippocampal cell death in the mice," Neuroscience Letters, vol. 416, no. 1, pp. 49-54, 2007.

[111] I. Ullah, H. Y. Park, and M. O. Kim, "Anthocyanins protect against kainic acid-induced excitotoxicity and apoptosis via ROS-activated AMPK pathway in hippocampal neurons," CNS Neuroscience and Therapeutics, vol. 20, no. 4, pp. 327-338, 2014.

[112] K. A. Lehtimäki, J. Peltola, E. Koskikallio, T. Keränen, and J. Honkaniemi, "Expression of cytokines and cytokine receptors in the rat brain after kainic acid-induced seizures," Molecular Brain Research, vol. 110, no. 2, pp. 253-260, 2003.

[113] K.-J. Jang, K.-H. Lee, S.-L. Kim et al., "Chongmyungtang attenuates kainic acid-induced seizure and mortal effect in the mouse," Archives of Pharmacal Research, vol. 20, no. 4, pp. 375378, 1997.

[114] Y. Sun, S. Yin, S. Li et al., "Effects of L-arginine on seizure behavior and expression of GFAP in kainic acid-treated rats," Neurophysiology, vol. 45, no. 1, pp. 21-25, 2013.

[115] I. Milenkovic, N. Nedeljkovic, R. Filipovic, S. Pekovic, L. Rakic, and M. Stojiljkovic, "Pattern of glial fibrillary acidic protein expression following kainate-induced cerebellar lesion in rats," Neurochemical Research, vol. 30, no. 2, pp. 207-213, 2005.

[116] A. Kanada, Y. Nishimura, J.-Y. Yamaguchi et al., "Extract of Ginkgo biloba leaves attenuates kainate-induced increase in intracellular $\mathrm{Ca}^{2+}$ concentration of rat cerebellar granule neurons," Biological and Pharmaceutical Bulletin, vol. 28, no. 5, pp. 934-936, 2005.

[117] A. A. Farooqui, M. L. Litsky, T. Farooqui, and L. A. Horrocks, "Inhibitors of intracellular phospholipase $\mathrm{A}_{2}$ activity: their neurochemical effects and therapeutical importance for neurological disorders," Brain Research Bulletin, vol. 49, no. 3, pp. 139-153, 1999.

[118] Y.-P. Sun, C.-K. Sun, M. Fan, D.-Y. Han, J. Zhao, and D.-Z. Gong, "Effect of no mediator on kainic acid induced behavioral seizures in rats," Chinese Journal of Applied Physiology, vol. 19, no. 2, pp. 185-188, 2003.

[119] M. S. Parihar and T. Hemnani, "Experimental excitotoxicity provokes oxidative damage in mice brain and attenuation by extract of Asparagus racemosus," Journal of Neural Transmission, vol. 111, no. 1, pp. 1-12, 2004.

[120] S. H. Oh, D.-E. Sok, and M. R. Kim, "Neuroprotective effects of butterbur and rough aster against kainic Acid-induced oxidative stress in mice," Journal of Medicinal Food, vol. 8, no. 2, pp. 169-176, 2005.

[121] T.-H. Lee, J.-G. Lee, J.-M. Yon et al., "Capsaicin prevents kainic acid-induced epileptogenesis in mice," Neurochemistry International, vol. 58, no. 6, pp. 634-640, 2011. 
[122] J.-Y. Han, S.-Y. Ahn, C.-S. Kim et al., "Protection of apigenin against kainate-induced excitotoxicity by anti-oxidative effects," Biological \& Pharmaceutical Bulletin, vol. 35, no. 9, pp. 14401446, 2012.

[123] Y. K. Gupta, S. Briyal, and M. Sharma, "Protective effect of curcumin against kainic acid induced seizures and oxidative stress in rats," Indian Journal of Physiology and Pharmacology, vol. 53, no. 1, pp. 39-46, 2009.

[124] Y.-H. Shih, Y.-C. Chein, J.-Y. Wang, and Y.-S. Fu, "Ursolic acid protects hippocampal neurons against kainate-induced excitotoxicity in rats," Neuroscience Letters, vol. 362, no. 2, pp. 136-140, 2004.

[125] H.-J. Kim, K.-D. Moon, S.-Y. Oh, S.-P. Kim, and S.-R. Lee, "Ether fraction of methanol extracts of Gastrodia elata, a traditional medicinal herb, protects against kainic acid-induced neuronal damage in the mouse hippocampus," Neuroscience Letters, vol. 314, no. 1-2, pp. 65-68, 2001.

[126] Y. K. Gupta and S. Briyal, "Protective effect of vineatrol against kainic acid induced seizures, oxidative stress and on the expression of heat shock proteins in rats," European Neuropsychopharmacology, vol. 16, no. 2, pp. 85-91, 2006.

[127] S. H. Oh, T. H. Sung, and M. R. Kim, "Ixeris dentata extract maintains glutathione concentrations in mouse brain tissue under oxidative stress induced by kainic acid," Journal of Medicinal Food, vol. 6, no. 4, pp. 353-358, 2003.

[128] D.-E. Sok, S. H. Oh, Y.-B. Kim, H.-G. Kang, and M. R. Kim, "Neuroprotection by extract of Petasites japonicus leaves, a traditional vegetable, against oxidative stress in brain of mice challenged with kainic acid," European Journal of Nutrition, vol. 45, no. 2, pp. 61-69, 2006.

[129] H. S. Cui, M. R. Kim, and D.-E. Sok, "Protection by petaslignolide A, a major neuroprotective compound in the butanol extract of Petasites japonicus leaves, against oxidative damage in the brains of mice challenged with kainic acid," Journal of Agricultural and Food Chemistry, vol. 53, no. 22, pp. 8526-8532, 2005.

[130] Q. Wang, S. Yu, A. Simonyi, G. Rottinghaus, G. Y. Sun, and A. Y. Sun, "Resveratrol protects against neurotoxicity induced by kainic acid," Neurochemical Research, vol. 29, no. 11, pp. 21052112, 2004.

[131] Y. K. Gupta, S. Briyal, and G. Chaudhary, "Protective effect of trans-resveratrol against kainic acid-induced seizures and oxidative stress in rats," Pharmacology Biochemistry \& Behavior, vol. 71, no. 1-2, pp. 245-249, 2002.

[132] P. F. Hsieh, C.-W. Hou, P.-W. Yao et al., "Sesamin ameliorates oxidative stress and mortality in kainic acid-induced status epilepticus by inhibition of MAPK and COX-2 activation," Journal of Neuroinflammation, vol. 8, article 57, 2011.

[133] C.-K. Wang, L.-G. Chen, C.-L. Wen et al., "Neuroprotective activity of vitis thunbergii var. taiwaniana extracts in vitro and in vivo," Journal of Medicinal Food, vol. 13, no. 1, pp. 170-178, 2010.

[134] M. S. Parihar and T. Hemnani, "Phenolic antioxidants attenuate hippocampal neuronal cell damage against kainic acid induced excitotoxicity," Journal of Biosciences, vol. 28, no. 1, pp. 121-128, 2003.

[135] K. S. Kang, Y. Wen, N. Yamabe, M. Fukui, S. C. Bishop, and B. T. Zhu, "Dual beneficial effects of (-)-epigallocatechin-3-gallate on levodopa methylation and hippocampal neurodegeneration: in vitro and in vivo studies," PLOS ONE, vol. 5, no. 8, Article ID e11951, 2010.
[136] L. Luo, Y. Jin, I. Kim, and J. Lee, "Glycyrrhizin attenuates kainic Acid-induced neuronal cell death in the mouse hippocampus," Experimental Neurobiology, vol. 22, no. 2, pp. 107-115, 2013.

[137] L.-Q. Ouyang, R.-S. Liang, W. Yang et al., "Effects of baicalin on the expression of IL-1beta; and TNF- and alpha; in the hippocampus of kainate-induced epileptic mice," Journal of International Neurology and Neurosurgery, vol. 39, no. 1, pp. 1619, 2012.

[138] K. B. Duffy, E. L. Spangler, B. D. Devan et al., "A blueberryenriched diet provides cellular protection against oxidative stress and reduces a kainate-induced learning impairment in rats," Neurobiology of Aging, vol. 29, no. 11, pp. 1680-1689, 2008.

[139] D. H. Kim, B. H. Yoon, W. Y. Jung et al., "Sinapic acid attenuates kainic acid-induced hippocampal neuronal damage in mice," Neuropharmacology, vol. 59, no. 1-2, pp. 20-30, 2010.

[140] P. N'Gouemo, M. Baldy-Moulinier, and C. Nguemby-Bina, "Effects of an ethanolic extract of Desmodium adscendens on central nervous system in rodents," Journal of Ethnopharmacology, vol. 52, no. 2, pp. 77-83, 1996.

[141] T.-Y. Lin, W.-J. Huang, C.-C. Wu, C.-W. Lu, and S.-J. Wang, "Acacetin inhibits glutamate release and prevents kainic acidinduced neurotoxicity in rats," PLOS ONE, vol. 9, no. 2, Article ID e88644, 2014.

[142] J.-S. Byun, Y. H. Han, S.-J. Hong et al., "Bark constituents from mushroom-detoxified Rhus verniciflua suppress kainic acidinduced neuronal cell death in mouse hippocampus," Korean Journal of Physiology and Pharmacology, vol. 14, no. 5, pp. 279283, 2010. 


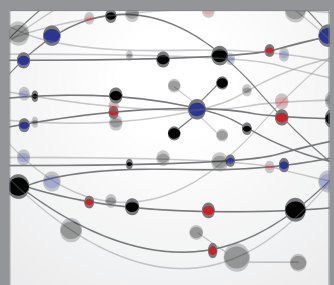

The Scientific World Journal
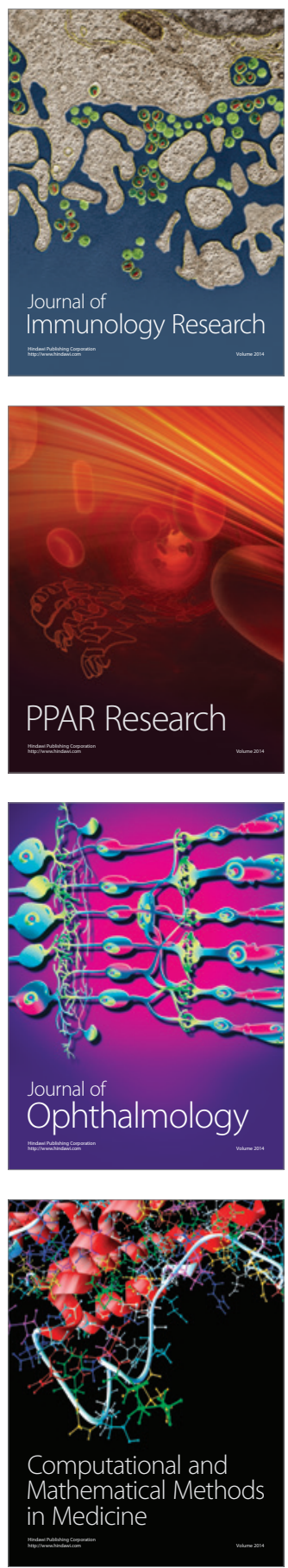

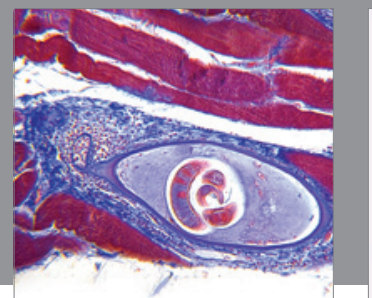

Gastroenterology

Research and Practice
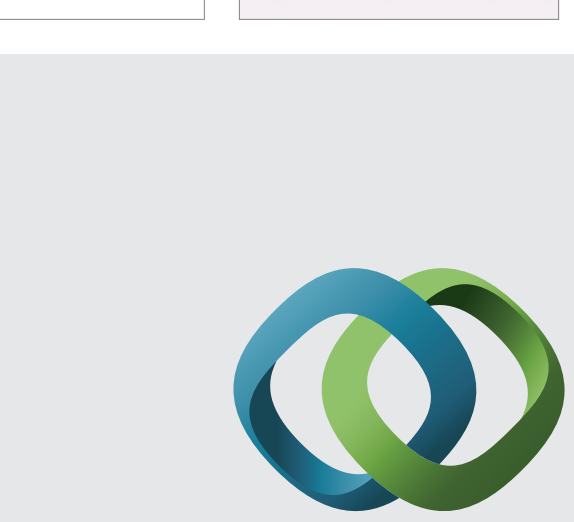

\section{Hindawi}

Submit your manuscripts at

http://www.hindawi.com
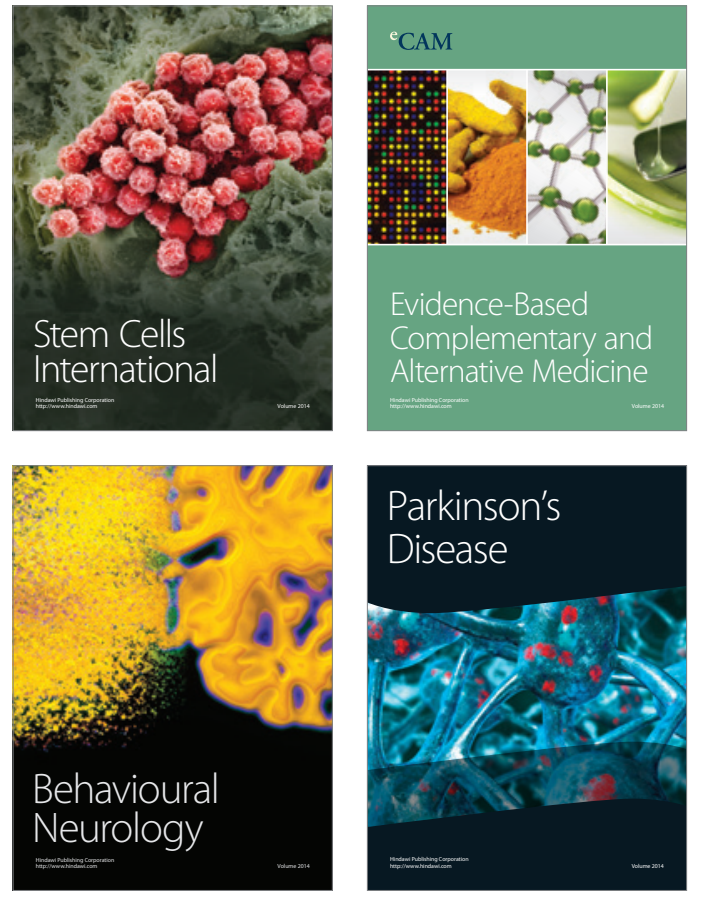
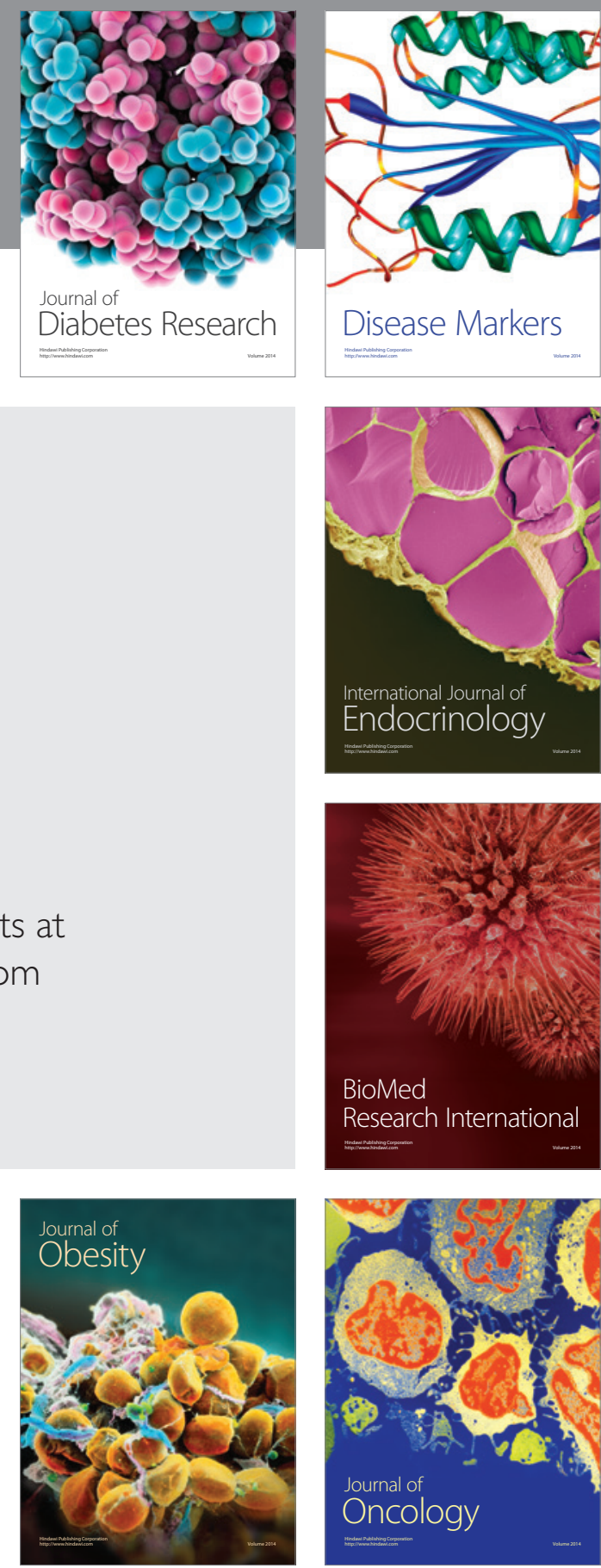

Disease Markers
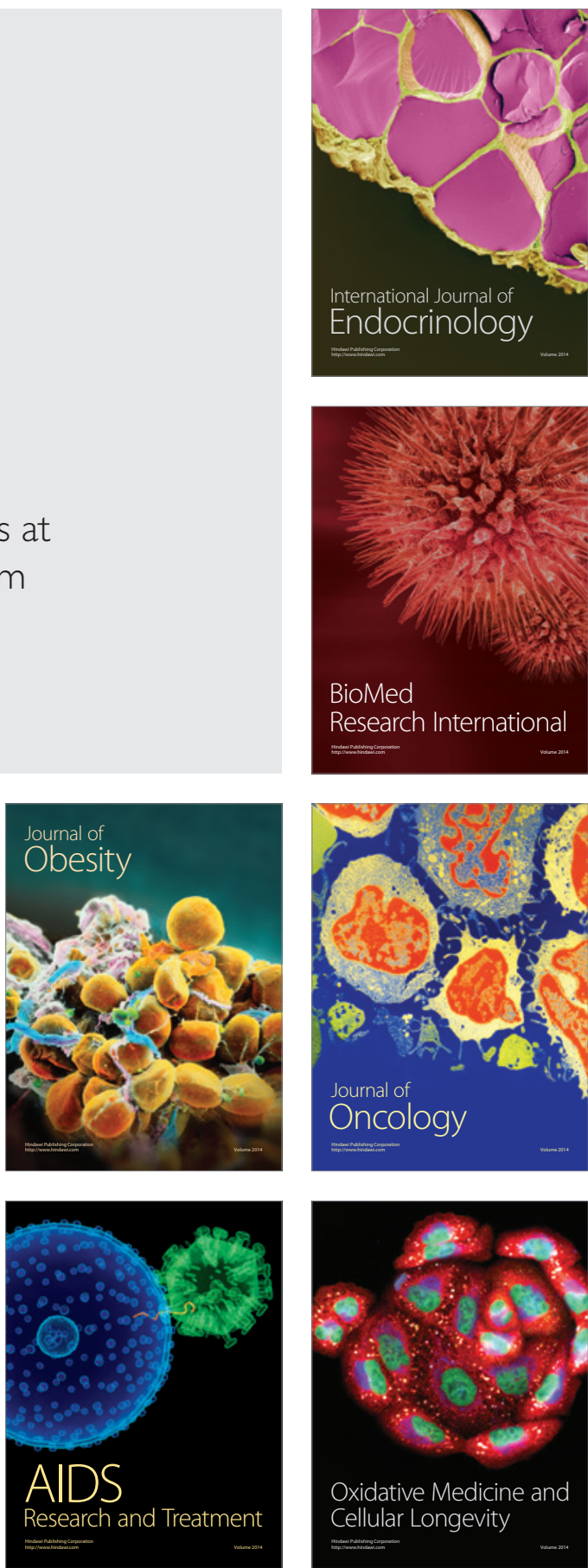